\title{
Commentary
}

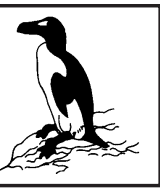

The Auk 121(2):610-618, 2004

\section{SEASONAL NICHES OF NEARCTIC-NEOTROPICAL MIGRATORY BIRDS: IMPLICATIONS FOR THE EVOLUTION OF MIGRATION}

\author{
Yoshinori Nakazawa, ${ }^{1}$ A. Townsend Peterson,${ }^{2,4}$ Enrique Martínez-Meyer, ${ }^{3}$ \\ and Adolfo G. Navarro-SigüenZA ${ }^{1}$ \\ ${ }^{1}$ Museo de Zoología, Facultad de Ciencias, Universidad Nacional Autónoma de México, \\ Apartado 70-399, D.F. 04510, México; \\ ${ }^{2}$ Natural History Museum and Biodiversity Research Center, The University of Kansas, Lawrence, Kansas 66045, USA; and \\ ${ }^{3}$ Department of Geography and Kansas Applied Remote Sensing Program, The University of Kansas, \\ Lawrence, Kansas 66045, USA
}

The Evolution of avian migratory systems has been of intense interest to ornithologists (Gauthreaux 1982; Berthold 1988, 1993; Levey and Stiles 1992; Rappole 1995; Chesser and Levey 1998). The consensus is that a sedentary ancestor began to move seasonally, within an ancestral distribution, in response to some influence-either a push (e.g. poor conditions on the ancestral distribution) or a pull (e.g. better conditions elsewhere)-and that local tracking eventually extended to long-distance, predictable movements (Berthold 1993, Rappole 1995). One particularly well-developed hypothesis is that local movements of tropical bird species tracking variable or uncertain resources (either food or space for breeding) evolved into regular seasonal and longer distance movements. That line of thought, originally based on NearcticNeotropical migrants (Levey and Stiles 1992, Rappole 1995), has been partially supported in an independent system, the austral migrants in South America (Chesser and Levey 1998).

New perspectives on the evolution of migration may prove useful (Zink 2002). A question that has not received sufficient attention is the degree to which a species is tracking a single set of conditions year-round-as opposed to changing from one ecological regime to another. Seasonal differences in habitat use by migratory birds are well known (see reviews in Keast and Morton 1980, Hagan and Johnston 1995).

\footnotetext{
${ }^{4}$ Address correspondence to this author. E-mail: town@ku.edu
}

However, a recent study (Joseph and Stockwell 2000) demonstrated that one austral migrant species, Swainson's Flycatcher (Myiarchus swainsoni), tracks a consistent temperature regime in its seasonal movements through the year. That result suggests an interesting aspect of migratory behavior: species' seasonal movements may be predictable on the basis of climate, with species effectively tracking a single climate regime (a climatic "niche") through the course of the year (much more precisely than simply tracking "summer-like" conditions yearround). With the approach having been tested on only a single species, and without sufficient sample sizes to permit rigorous statistical tests in that example, we are unable to determine the generality of "niche-tracking" as opposed to "niche-switching." If different aspects of species' seasonal movements reflect conservatism in ecological characteristics versus seasonal differences, conserved patterns may greatly inform related issues, such as directionality of change, ancestral distributional areas, and others, that are key for understanding features of the evolution of migration.

Here, we extend the initial evaluation (Joseph and Stockwell 2000) of tracking of seasonal conditions in migratory birds to a broad sample of Nearctic-Neotropical species, in the context of coarse-scale ecological niches of species. We follow Grinnell's $(1917,1924)$ geographic view of ecological niches, defining them as suites of ecological conditions within which a species can maintain populations without immigration. Because our point of view is essentially 
geographic, our "niche models" are necessarily cast in dimensions that are manifested at broad spatial scales (e.g. climate and topography), although niches clearly have additional dimensions at finer spatial scales. In a number of contexts, models of ecological niches developed in "pure" autecological dimensions-excluding both biological interactions and spatial variables that link the niche to particular places on Earth-have been shown to provide excellent predictability regarding many complex phenomena of biodiversity (Panetta and Dodd 1987; Huntley et al. 1989, 1995; Richardson and McMahon 1992; Sutherst et al. 1999; Hoffmann 2001; Peterson and Vieglais 2001; Anderson et al. 2002; Peterson et al. 2002b, c; Peterson 2003; Peterson and Kluza 2003). Here, we model ecological niches for single species in different seasons and assess degree of coincidence among seasonal ecological niches. We identify species that track a single climatic niche among seasons - in contrast to others that appear to switch niche conditions. Our results demonstrate additional complexity in the evolution of avian migratory systems and in their current diversity.

\section{Methods for Predictions of Seasonal Niches ANd Distributions}

Study species and data.-Species chosen for testing (1) showed marked seasonal movements (American Ornithologists' Union 1998), (2) met minimum sample-size requirements ( $n=20$ spatially unique occurrence points) for both breeding (May-July) and wintering (November-February) areas, and (3) had distributional areas in both seasons with significant representation in North America south to the Mexico-Guatemala border. In this initial exploration, we wanted to know if higher taxa would present variation in seasonal niche characteristics, so a final criterion (4) was that species for analysis belonged to genera including multiple species that met the first three criteria. Twentyone species of four genera met those criteria and were selected for analysis: Dendroica (nine species), Spizella (four species), Vermivora (three species), and Vireo (five species).

Distributional data (i.e. geographic coordinates of known occurrences) were drawn from two principal sources: U.S. Breeding Bird Survey (BBS) and Atlas of Mexican Bird
Distributions (A. G. Navarro-Sigüenza et al. unpubl. data). The BBS data were downloaded from the U.S. Geological Survey website (see Acknowledgments) and uploaded into Microsoft ACCESS for manipulation and preparation. Because BBS data include only breeding records, no restrictions were placed on dates of records. However, the Atlas of Mexican Bird Distributions was compiled from specimen tag data from 34 natural history museums (Peterson et al. 1998; see Acknowledgments). Wintering records (November to February) and breeding records (May to July) were extracted for focal species. Records were georeferenced by hand to the nearest $0.1^{\prime}$ of latitude-longitude via reference to 1:50,000 topographic maps. Although much more distributional information clearly exists for those species, our sources provided more-than-sufficient information for development of predictive models (Stockwell and Peterson 2002b).

Climatic data were provided by the Intergovernmental Panel on Climate Change (IPCC; see Acknowledgments), and digitalelevation model (DEM) data by the Defense Mapping Agency (see Acknowledgments). All coverages were generalized to $0.1 \times 0.1$ pixel resolution for analysis. The DEM data set summarized elevation, slope, and aspect. The IPCC data set provided monthly means that we summarized as mean values for each season (MayAugust, November-February; months chosen to coincide as best as possible with periods that species spend on their breeding and wintering distributional areas) for diurnal temperature range; frost days; minimum, mean, and maximum temperature; and vapor pressure.

Ecological-niche modeling. - The ecological niche of a species can be defined as the conjunction of ecological conditions within which it can maintain populations without immigration (MacArthur 1972). Several approaches have been used to approximate species' ecological niches (Austin et al. 1990); a very robust option is the genetic algorithm for rule-set prediction (GARP), which includes several inferential approaches in an iterative, evolutionary computing approach (Stockwell and Noble 1992, Stockwell 1999, Stockwell and Peters 1999). Extensive testing has demonstrated GARP's ability to predict ecological and geographic distributions of species in diverse ecological, geographic, and taxonomic contexts (Peterson 2001; Peterson et al. 2001, 
2002a, b, c; Peterson and Vieglais 2001; Feria and Peterson 2002; Stockwell and Peterson 2002a, b). Although many of those dimensions are clearly intercorrelated (e.g. temperature and elevation), GARP uses machine learning to avoid problems with redundancy of information and highly correlated factors (Stockwell and Noble 1992, Stockwell 1999, Stockwell and Peters 1999). We used a desktop version of GARP to generate our models (see Acknowledgments).

The algorithm works in an iterative process of rule selection, evaluation, testing, and incorporation or rejection to produce a heterogeneous (e.g. logistic regression, bioclimatic rules) set of rules (i.e. IF-THEN statements delineating a subsector of ecological space) describing the species' ecological niche. Ecological-niche models developed with GARP can be projected onto landscapes via spatial queries to detect conditions fitting those modeled as the species' niche; projection onto the landscape from which inputoccurrence points were taken indicates the geographic distribution of suitable conditions (a potential geographic distribution for the species). Those models can also be projected onto alternative landscapes, such as another continent, to predict species invasions (Peterson and Vieglais 2001), or onto another climate regime to predict climate-change effects (Peterson et al. 2001, 2002b). Here, we project models onto climatic conditions in another season to predict seasonal distributions of species.

Because GARP is a random-walk procedure, results vary from modeling run to modeling run; that intermodel variation effectively constitutes a bootstrap manipulation and, thus, provides a measure of robustness of results. To optimize model performance, we developed 100 replicate models of the species' ecological niche, based on random $50 \%$ subsets of available occurrence points (i.e. half of the occurrence points were used to build models, and the other half used to test their predictive ability). Unlike previous applications, which either used single models to predict species' distributions (Peterson et al. 1999) or summed multiple models to incorporate model-to-model variation (Peterson et al. 2004), we used a new procedure (Anderson et al. 2003) for choosing best subsets of models. The procedure is based on the observations that (1) models vary in quality, (2) variation among models involves an inverse relationship between errors of omission (leaving out true distributional area) and commission (including areas not actually habitable), and (3) best models (as judged by experts blind to error statistics in the original derivation of the method) are clustered in a region of minimum omission of independent test points and moderate area predicted (an axis related directly to commission error). Position of the cloud of points relative to the two error axes provides an assessment of the relative accuracy of each model. To choose best subsets of models, we (1) eliminated all models but those with no omission error based on the independent test points, (2) calculated the average area predicted present among these zero-omission models (percentage of the area analyzed), and (3) identified the 10 models that were closest to the overall average extent for each species and season. Those 10 models and their projections to the other season were then summed to provide a best summary of the results of GARP modeling for the species-season.

For each species in each season, we projected the ecological niche model onto the same season (autoprediction) and onto the "other" season (alloprediction). Model efficacy was tested originally via a random $50 \%$ partition of input data in autoprediction; half of the points (test points) were set aside prior to modeling and overlaid on the resulting prediction, and model significance was evaluated as follows (Peterson et al. 1999): (1) expected frequencies of successful prediction under a random model were calculated as the product of number of test points and proportion of the study area (all of North America) predicted present, and (2) a chi-square test $(\mathrm{df}=$ 1) was used to test for significant deviation (in the positive direction) from random expectations. It is worth noting that this test is not biased by ecological or geographic breadth of predictions-small areas predicted fare worse in inclusion of points-but require lower numbers of successful predictions to achieve significance.

For allopredictions, points from the "other" season were overlain on the projection to the "other" season. That is, for a model developed based on the breeding season, we projected it onto winter climate surfaces, and then overlaid the wintering occurrence points. Coincidence of points and prediction were then tested using chi-square tests similar to those used to test autopredictions, again assessing coincidence at the level of all of North America. 


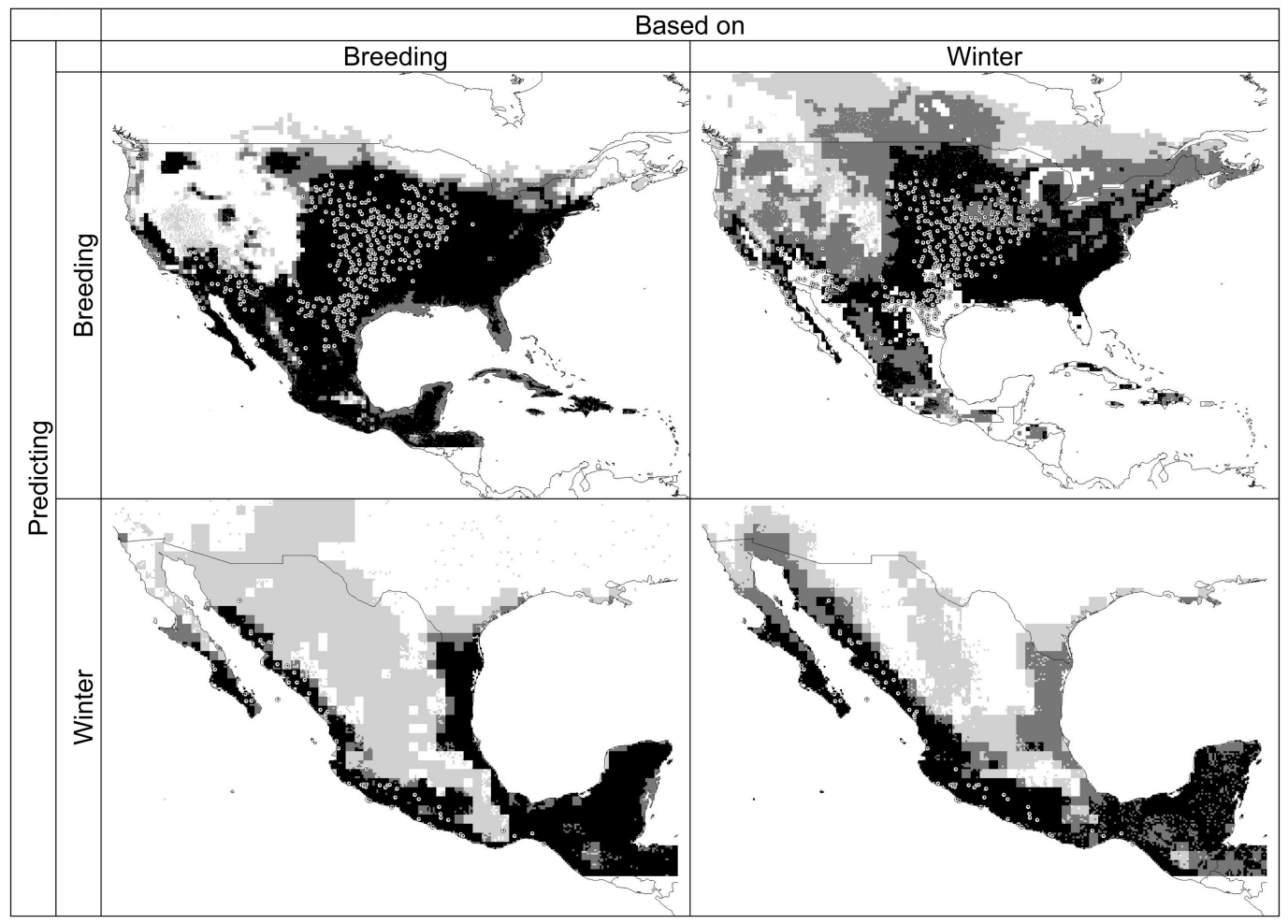

FIG. 1. Results of reciprocal interpredictions of seasonal distributions of Bell's Vireo. Models based on breeding distributions or on winter distributions are each used to predict distributions in the same (autoprediction) and the other season (alloprediction). Points overlain are the known distributional occurrences for the species in that particular season.

\section{Seasonal Niches and Distributions of Twenty-One Migratory Birds}

All models were highly statistically significant in autoprediction. That is, on the basis of $50 \%$ random splits of input data, the models predicted the distribution of the independent test data set significantly better than random models, as has been found in previous analyses using the same data sets (Peterson 2001, Peterson et al. 2002a). In fact, across all breeding-season models, the least significant model was significant at $P<0.005$, and $99 \%$ of models were significant at $P<10^{-33}$; for wintering models, the least significant models were significant at $P<10^{-9}$, and $90 \%$ of models were significant at $P<10^{-39}$.

Allopredictions, in which the model of one season was used to predict the species' geographic distribution in the other season, were variable in significance. Seasonal distributions of some species, such as Bell's Vireo (Vireo bellii), were predicted with high statistical significance in allopredictions (Fig. 1). In this example, the winter distributional prediction based on the breeding-season model was almost exactly coincident with the autoprediction for the winter distribution, and likewise for the breeding season. In all, 26 of 42 reciprocal predictions were significant $(P<0.05)$, and another prediction was marginally significant $(0.1>P>0.05)$ (Table 1$)$.

The remainder of the species showed a very different pattern. For those species, seasonal allopredictions had very little explanatory power for the "other" season. For example, for Magnolia Warbler (Dendroica magnolia), the allopredicted winter distribution was across the Gulf coast of the United States; whereas the actual winter distribution was in southeastern Mexico (and farther south) (Fig. 2). Similarly, the allopredicted breeding distribution was across the Great Plains of the central United States, but the actual breeding distribution is 
TABLE 1. Summary of species tested, sample sizes available, and results of tests of interpredictivity between seasons $\left(n=\right.$ total number of unique occurrence points available for that species-season combination, $n_{y}=$ number of unique occurrence points successfully predicted by the model for the "other" season, \% area = percentage of total area in North America predicted present by the model from the "other" season, $\chi^{2}=$ chisquare statistic calculated as described in the text, $P=$ corresponding probability value based on $\mathrm{df}=1$ ).

\begin{tabular}{|c|c|c|c|c|c|c|c|}
\hline Species & Season & $n$ & $n_{y}$ & $\%$ area & $\chi^{2}$ & $P$ & $\begin{array}{c}\text { Significantly } \\
\text { better than } \\
\text { expected }\end{array}$ \\
\hline \multirow[t]{2}{*}{ Dendroica aestiva } & $\mathrm{b}$ & 3,246 & 1,328 & 24.43815 & 477.0478 & $9.4 \times 10^{-106}$ & $\mathrm{a}$ \\
\hline & $\mathrm{w}$ & 133 & 17 & 5.342713 & 14.55436 & 0.000136 & a \\
\hline \multirow[t]{2}{*}{ D. audubonic } & $\mathrm{b}$ & 721 & 109 & 4.550468 & 185.3718 & $3.26 \times 10^{-42}$ & a \\
\hline & $\mathrm{w}$ & 143 & 138 & 95.8814 & 0.14014 & 0.708142 & \\
\hline \multirow[t]{2}{*}{ D. coronata $^{c}$} & $\mathrm{~b}$ & 999 & 3 & 13.90291 & 154.4244 & $1.87 \times 10^{-35}$ & \\
\hline & $\mathrm{w}$ & 57 & 0 & 0.019402 & 0.011061 & 0.916239 & \\
\hline \multirow[t]{2}{*}{ D. dominica } & $\mathrm{b}$ & 708 & 35 & 1.371428 & 66.78801 & $3.02 \times 10^{-16}$ & a \\
\hline & $\mathrm{w}$ & 24 & 15 & 1.952767 & 459.5302 & $6.1 \times 10^{-102}$ & a \\
\hline \multirow{2}{*}{ D. magnolia ${ }^{c}$} & $\mathrm{~b}$ & 787 & 6 & 12.55124 & 99.65007 & $1.82 \times 10^{-23}$ & \\
\hline & $\mathrm{w}$ & 50 & 0 & 1.361727 & 0.690263 & 0.406075 & \\
\hline \multirow[t]{2}{*}{ D. nigrescens } & $\mathrm{b}$ & 377 & 155 & 19.28155 & 115.4606 & $6.24 \times 10^{-27}$ & a \\
\hline & $\mathrm{w}$ & 71 & 70 & 93.12885 & 3.311003 & 0.068817 & $\mathrm{~b}$ \\
\hline \multirow[t]{2}{*}{ D. occidentalis ${ }^{c}$} & $\mathrm{~b}$ & 149 & 0 & 0.234979 & 0.350943 & 0.55358 & \\
\hline & $\mathrm{w}$ & 49 & 49 & 48.8975 & 51.20961 & $8.3 \times 10^{-13}$ & a \\
\hline \multirow[t]{2}{*}{ D. townsendi ${ }^{\mathrm{c}}$} & $\mathrm{b}$ & 316 & 0 & 0.222403 & 0.704361 & 0.401322 & \\
\hline & $\mathrm{w}$ & 66 & 0 & 1.361009 & 0.91066 & 0.339939 & \\
\hline \multirow[t]{2}{*}{ D. virens ${ }^{c}$} & $\mathrm{~b}$ & 923 & 3 & 10.39835 & 100.5233 & $1.17 \times 10^{-23}$ & \\
\hline & $\mathrm{w}$ & 61 & 22 & 3.193412 & 213.2193 & $2.73 \times 10^{-48}$ & a \\
\hline \multirow[t]{2}{*}{ Spizella atrogularis } & $\mathrm{b}$ & 132 & 0 & 0.015809 & 0.020871 & 0.885131 & \\
\hline & $\mathrm{w}$ & 37 & 21 & 5.391937 & 191.364 & $1.6 \times 10^{-43}$ & a \\
\hline \multirow[t]{2}{*}{ S. breweri } & $\mathrm{b}$ & 628 & 372 & 14.06064 & 1060.619 & $1.2 \times 10^{-232}$ & a \\
\hline & $\mathrm{w}$ & 33 & 27 & 95.93135 & 16.84036 & $4.07 \times 10^{-5}$ & \\
\hline \multirow[t]{2}{*}{ S. pallida } & $\mathrm{b}$ & 687 & 400 & 24.80356 & 411.4094 & $1.81 \times 10^{-91}$ & a \\
\hline & $\mathrm{w}$ & 94 & 4 & 3.136284 & 0.387471 & 0.533632 & \\
\hline \multirow[t]{2}{*}{ S. passerina } & $\mathrm{b}$ & 3,540 & 315 & 5.148694 & 101.9143 & $5.8 \times 10^{-24}$ & a \\
\hline & $\mathrm{w}$ & 148 & 57 & 5.526672 & 308.4397 & $4.78 \times 10^{-69}$ & a \\
\hline \multirow[t]{2}{*}{ Vermivora celata } & $\mathrm{b}$ & 805 & 340 & 42.39139 & 0.007957 & 0.92892 & \\
\hline & $\mathrm{w}$ & 181 & 171 & 68.349 & 57.10962 & $4.12 \times 10^{-14}$ & a \\
\hline \multirow[t]{2}{*}{$V \cdot$ peregrina $^{c}$} & $\mathrm{~b}$ & 565 & 0 & 0.584213 & 3.320202 & 0.068433 & \\
\hline & $\mathrm{w}$ & 22 & 0 & 0.319054 & 0.070416 & 0.790731 & \\
\hline \multirow[t]{2}{*}{ V. ruficapilla } & $\mathrm{b}$ & 988 & 698 & 41.69328 & 340.725 & $4.44 \times 10^{-76}$ & a \\
\hline & $\mathrm{w}$ & 112 & 12 & 1.923305 & 45.88584 & $1.25 \times 10^{-11}$ & a \\
\hline \multirow[t]{2}{*}{ Vireo bellii } & $\mathrm{b}$ & 447 & 295 & 16.13449 & 821.2803 & $1.3 \times 10^{-180}$ & a \\
\hline & $\mathrm{w}$ & 75 & 59 & 3.472225 & 1265.239 & $4 \times 10^{-277}$ & a \\
\hline \multirow[t]{2}{*}{ Vi. cassinii } & $\mathrm{b}$ & 425 & 4 & 0.039163 & 88.32986 & $5.54 \times 10^{-21}$ & a \\
\hline & $\mathrm{w}$ & 26 & 26 & 86.19518 & 4.164101 & 0.041289 & a \\
\hline \multirow[t]{2}{*}{ Vi. gilvus } & $\mathrm{b}$ & 2,617 & 1,891 & 36.68328 & 1425.961 & 0 & a \\
\hline & $\mathrm{w}$ & 129 & 72 & 5.89962 & 578.9284 & $6.4 \times 10^{-128}$ & a \\
\hline \multirow[t]{2}{*}{ Vi. griseus } & $\mathrm{b}$ & 1,347 & 482 & 14.0937 & 523.3807 & $7.8 \times 10^{-116}$ & a \\
\hline & $\mathrm{w}$ & 98 & 69 & 2.7716 & 1663.663 & 0 & a \\
\hline \multirow[t]{2}{*}{ Vi. huttoni } & $\mathrm{b}$ & 388 & 38 & 4.136201 & 31.32145 & $2.19 \times 10^{-8}$ & a \\
\hline & $\mathrm{w}$ & 78 & 42 & 3.592588 & 568.7357 & $1.1 \times 10^{-125}$ & a \\
\hline
\end{tabular}

${ }^{\mathrm{a}} \mathrm{P}<0.05$.

${ }^{\mathrm{b}} 0.05<P<0.1$.

'Species breeding in the spruce biome. 


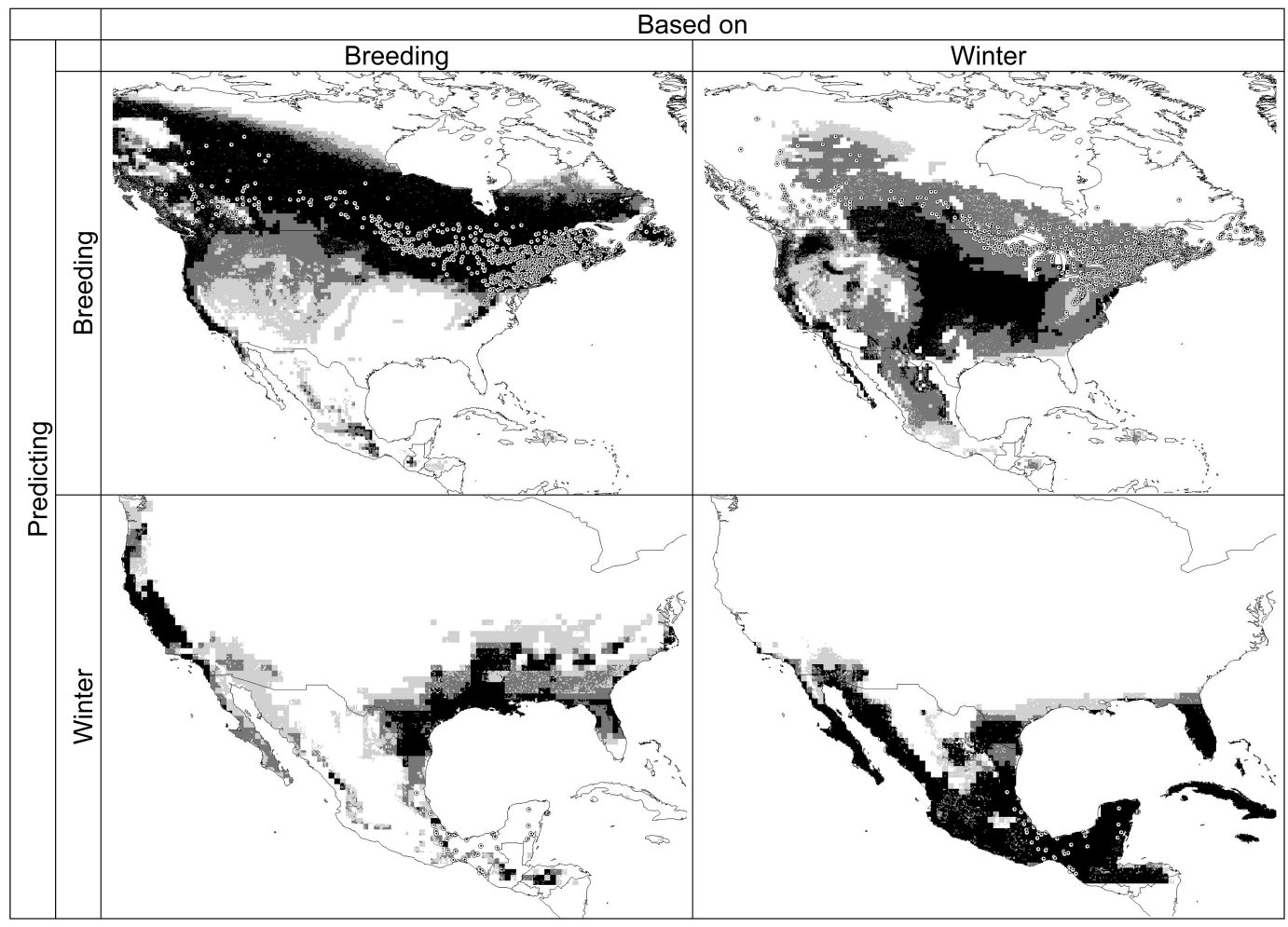

FIG. 2. Results of reciprocal interpredictions of seasonal distributions of Magnolia Warbler. Models based on breeding distributions or on winter distributions are each used to predict distributions in the same (autoprediction) and the other season (alloprediction). Points overlain are the known distributional occurrences for the species in that particular season.

across central Canada (Fig. 2). Several comparisons (16 of 42) showed that sort of complete disconnect between the two seasons, with negligible interpredictive ability (Table 1; Fig. 3).

In sum, of the 21 species analyzed, 10 species were highly statistically significant in both allopredictions, 7 showed mixed predictions (i.e. one alloprediction significant, one not), and 4 were decidedly nonsignificant in both allopredictions (Fig. 3). Mixed predictions may indicate that statistical power was insufficient to detect a real relationship, or that one niche is nestled within another in ecological space, thus leading to asymmetric predictions (MartínezMeyer 2002). All Vireo species analyzed were highly predictive in both allopredictions, whereas other genera showed mixed results.

\section{Discussion}

The results of the study indicate the existence of broad variation in seasonal ecology of species:

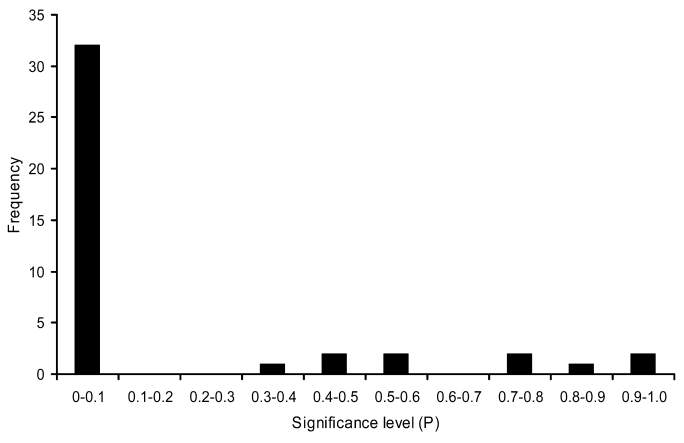

FIG. 3. Frequency distribution of significance values in reciprocal interpredictions (breeding distribution predicts winter distribution, winter distribution predicts breeding distribution).

some species (in fact, the majority of those tested) effectively follow a particular climatic niche throughout the year, whereas others make a clear switch in climate regimes between seasons. 
The former group ("niche followers," as defined at coarse spatial scales) can be seen perhaps as closely adapted to conditions or resources tied to a very consistent climate regime (Root 1988), whereas the latter group makes a qualitative shift between seasons - a result that has interesting implications for the evolution of migratory systems. Although seasonal variation in habitat use is well known and thoroughly documented (Keast and Morton 1980, Hagan and Johnston 1995), such variation among taxa in terms of niche-following versus niche-switching has not been documented previously.

The hypothesis for the evolution of migration systems that seems best supported (Levey and Stiles 1992) involves a multistep process: (1) a resident species (tropical or subtropical) tracks locally varying resources, (2) resource-tracking becomes extended to longer distances, and (3) species evolve consistent movement tendencies in relation to seasonal stimuli. This series of steps is hypothesized to produce the regular, long-distance migratory patterns observed in many species around the world.

Our results suggest a further step in the evolution of complex migratory systems. Nichefollowing species can be seen as simply tracking a mobile climate regime (and, presumably, associated resources). Niche-switching species add a level of complexity, switching between distinct ecological regimes in different seasons. If the Levey-Stiles hypothesis is a valid basis for further speculation, the evolution of migratory systems may include additional steps beyond the three described above. Initial evolution of long-distance migration likely resulted in niche-followers; derivation of complex seasonal ecological switches is a likely fourth step in the process. Rigorous testing of these ideas in a phylogenetic framework would be very illuminating (Zink 2002).

More clear, however, is a possible association between niche-switching and the spruce biome ("northern boreal forest") of the northern United States and southern and central Canada. Indeed, of the seven species tested that are distributed broadly in the spruce biome (Table 1), none is clearly a niche-follower (i.e. both interpredictions significantly better than random): three are mixed, and four are clearly niche-switchers. That tendency (seen in Fig. 2), particularly if found to hold across a broader swath of species, suggests that invasion of northern forests may have required the evolution of niche-switching capability, because winter climate regimes for those species appear to be too far north for the consistent survival of small insectivorous birds, such as those examined here.

Finally, and most generally, the idea of nichefollowing versus niche-switching is an unexplored frontier in understanding the diversity of migratory systems. Joseph and Stockwell (2000) provided the framework (testing seasonal predictivity of distributions based on climatic niches) and applied the method to a first challenge (a South American austral migrant); we have extended its application in a more testable and quantitative framework and applied it to 21 additional species. The tracking-versusswitching concept is new to the literature on the evolution of avian migratory systems (Rappole 1995). Broader surveys-combining broader geographic areas with more distributional data on wintering grounds and better phylogenetic hypotheses - will lead to a more comprehensive understanding of the phenomenon.

\section{Acknowledgments}

We thank R. Scachetti-Pereira and D. Stockwell for development of the predictive algorithms, and L. Joseph and D. Stockwell for developing the original idea for this sort of analysis. D. Levey provided extensive and helpful commentary on a version of the manuscript. The following scientific collections kindly made data and specimens available to us for use in this study: American Museum of Natural History; Academy of Natural Sciences of Philadelphia; Bell Museum of Natural History; British Museum (Natural History); California Academy of Sciences; Carnegie Museum of Natural History; Canadian Museum of Nature; Denver Museum of Natural History; Delaware Museum of Natural History; Fort Hays State College; Field Museum of Natural History; Iowa State University; University of Kansas; Los Angeles County Museum of Natural History; Natuurhistorische Museum; Louisiana State University Museum of Zoology; Museum of Comparative Zoology, Harvard University; Moore Laboratory of Zoology, Occidental College; Museum Nationale d'Histoire Naturelle; Museum of Vertebrate Zoology, Berkeley; Museo de Zoología, Facultad de Ciencias, Universidad Nacional Autónoma de México; University of Nebraska; Royal Ontario Museum; San Diego Natural History Museum; Southwestern College; Texas Cooperative Wildlife Collections; University of Arizona; University of British Columbia Museum of Zoology; University of California Los Angeles, Museum of Vertebrate Zoology; Universidad Michoacana de San Nicolás de Hidalgo; United States National Museum 
of Natural History; Western Foundation of Vertebrate Zoology; and Peabody Museum, Yale University. Financial support was provided by the National Science Foundation.

For information on the U.S. Breeding Bird Survey (BBS), see www.mp2-pwrc.usgs.gov/bbs/. For information on the Intergovernmental Panel on Climate Change (IPCC), see www.ipcc.ch/. For information on the Defense Mapping Agency and digital elevation models (DEM), see edcdaac.usgs.gov/gtopo30/hydro/ namerica.html. For information on a desktop version of GARP, see www.lifemapper.org/desktopgarp.

\section{Literature Cited}

American Ornithologists' Union. 1998. Checklist of North American Birds, 7th ed. American Ornithologists' Union, Washington, D.C.

Anderson, R. P., M. Laverde, and A. T. Peterson. 2002. Using niche-based GIS modeling to test geographic predictions of competitive exclusion and competitive release in South American pocket mice. Oikos 93:3-16.

Anderson, R. P., D. Lew, And A. T. Peterson. 2003. Using error distributions to select best subsets of predictive models of species' distributions. Ecological Modelling 162:211-232.

Austin, M. P., A. O. Nicholls, and C. R. Margules. 1990. Measurement of the realized qualitative niche: Environmental niches of five Eucalyptus species. Ecological Monographs 60:161-177.

Berthold, P. 1988. The control of migration in European warblers. Pages 215-249 in Acta XIX Congressus Internationalis Ornithologici $(\mathrm{H}$. Ouellet, Ed.). National Museum of Natural Sciences, Ottawa, Ontario.

Berthold, P. 1993. Bird Migration: A General Survey. Oxford University Press, Oxford.

Chesser, R. T., And D. J. Levey. 1998. Austral migrants and the evolution of migration in New World birds: Diet, habitat, and migration revisited. American Naturalist 152:311-319.

Feria, T. P., And A. T. Peterson. 2002. Using point occurrence data and inferential algorithms to predict local communities of birds. Diversity and Distributions 8:49-56.

Gauthreaux, S. A. 1982. The ecology and evolution of avian migration systems. Pages 93-168 in Avian Biology, vol. 6 (D. S. Farner, J. R. King, and K. C. Parkes, Eds.). Academic Press, New York.

Grinnell, J. 1917. Field tests of theories concerning distributional control. American Naturalist 51:115-128.

Grinnell, J. 1924. Geography and evolution. Ecology 5:225-229.

Hagan, J. M., III, And D. W. Johnston, Eds. 1995. Ecology and Conservation of Neotropical
Migrant Landbirds. Smithsonian Institution Press, Washington, D.C.

Hoffmann, M. H. 2001. The distribution of Senecio vulgaris: Capacity of climatic range models for predicting adventitious ranges. Flora 196: 395-403.

Huntley, B., P. J. Bartlein, and I. C. Prentice. 1989. Climatic control of the distribution and abundance of beech (Fagus L.) in Europe and North America. Journal of Biogeography 16: 551-560.

Huntley, B., P. M. Berry, W. Cramer, and A. P. MCDonald. 1995. Modelling present and potential future ranges of some European higher plants using climate response surfaces. Journal of Biogeography 22:967-1001.

Joseph, L., AND D. R. B. Stockwell. 2000. Temperature-based models of the migration of Swainson's Flycatcher (Myiarchus swainsoni) across South America: A new use for museum specimens of migratory birds. Proceedings of the Academy of Natural Sciences of Philadelphia 150:293-300.

Keast, A., And E. S. Morton, Eds. 1980. Migrant Birds in the Neotropics: Ecology, Behavior, Distribution and Conservation. Smithsonian Institution Press, Washington, D.C.

Levey, D. J., AND F. G. Stiles. 1992. Evolutionary precursors of long-distance migration: Resource availability and movement patterns in Neotropical landbirds. American Naturalist 140:467-491.

MacArthur, R. H. 1972. Geographical Ecology. Princeton University Press, Princeton, New Jersey.

Martínez-Meyer, E. 2002. Evolutionary trends in ecological niches of species. Ph.D. dissertation, University of Kansas, Lawrence.

PAnetTA, F. D., And J. Dodd. 1987. Bioclimatic prediction of the potential distribution of skeleton weed Chondrilla juncea L. in western Australia. Journal of the Australian Institute of Agricultural Science 53:11-16.

Peterson, A. T. 2001. Predicting species' geographic distributions based on ecological niche modeling. Condor 103:599-605.

Peterson, A. T. 2003. Predicting the geography of species' invasions via ecological niche modeling. Quarterly Review of Biology 78: 419-433.

Peterson, A. T., L. G. Ball, and K. C. Cohoon. 2002a. Predicting distributions of tropical birds. Ibis 144:e27-e32.

Peterson, A. T., And D. A. Kluza. 2003. New distributional modeling approaches for GAP analysis. Animal Conservation 6:47-54.

Peterson, A. T., A. G. Navarro-Sigüenza, and H. Benitez-Diaz. 1998. The need for continued 
scientific collecting: A geographic analysis of Mexican bird specimens. Ibis 140:288-294.

Peterson, A. T., M. A. Ortega-Huerta, J. Bartley, V. Sánchez-Cordero, J. Soberón, R. H. Buddemeier, and D. R. B. Stockwell. 2002b. Future projections for Mexican faunas under global climate change scenarios. Nature 416: 626-629.

Peterson, A. T., V. Sánchez-Cordero, J. Soberón, J. Bartley, R. H. Buddemeier, and A. G. Navarro-Sigüenza. 2001. Effects of global climate change on geographic distributions of Mexican Cracidae. Ecological Modelling 144: 21-30.

Peterson, A. T., R. Scachetti-Pereira, and W. W. Hargrove. 2004. Potential distribution of Asian longhorned beetles (Anoplophora glabripennis) in North America. American Midland Naturalist. In press.

Peterson, A. T., J. Soberón, and V. SánchezCordero. 1999. Conservatism of ecological niches in evolutionary time. Science 285: 1265-1267.

Peterson, A. T., D. R. B. Stockwell, and D. A. KLuZA. 2002c. Distributional prediction based on ecological niche modeling of primary occurrence data. Pages 617-623 in Predicting Species Occurrences: Issues of Scale and Accuracy (J. M. Scott, P. J. Heglund, M. L. Morrison, J. B. Haufler, M. G. Raphael, W. A. Wall, and F. B. Samson, Eds.). Island Press, Washington, D.C.

Peterson, A. T., and D. A. Vieglais. 2001. Predicting species invasions using ecological niche modeling. BioScience 51:363-371.

Rappole, J. H. 1995. The Ecology of Migrant Birds: A Neotropical Perspective. Smithsonian Institution Press, Washington, D.C.

Richardson, D. M., AND J. P. McMahon. 1992. A bioclimatic analysis of Eucalyptus nintens to identify potential planting regions in southern Africa. South African Journal of Science 88: 380-387.
Rooт, T. 1988. Environmental factors associated with avian distributional boundaries. Journal of Biogeography 15:489-505.

Stоскwell, D. R. B. 1999. Genetic algorithms II. Pages 123-144 in Machine Learning Methods for Ecological Applications (A. H. Fielding, Ed.). Kluwer Academic Publishers, Boston.

Stockwell, D. R. B., and I. R. Noble. 1992. Induction of sets of rules from animal distribution data: A robust and informative method of analysis. Mathematics and Computers in Simulation 33:385-390.

Stockwell, D. R. B., and D. P. Peters. 1999. The GARP modelling system: Problems and solutions to automated spatial prediction. International Journal of Geographic Information Systems 13:143-158.

Stockwell, D. R. B., and A. T. Peterson. 2002a. Controlling bias in biodiversity data. Pages 537-546 in Predicting Species Occurrences: Issues of Scale and Accuracy (J. M. Scott, P. J. Heglund, M. L. Morrison, J. B. Haufler, M. G. Raphael, W. A. Wall, and F. B. Samson, Eds.). Island Press, Washington, D.C.

Stockwell, D. R. B., and A. T. Peterson. 2002b. Effects of sample size on accuracy of species distribution models. Ecological Modelling 148: 1-13.

Sutherst, R. W., G. F. Maywald, T. Yonow, and P. M. Stevens. 1999. CLIMEX User GuidePredicting the Effects of Climate on Plants and Animals. Commonwealth Scientific and Industrial Research Organisation (CSIRO) Publishing, Collingwood, Victoria, Australia.

ZINK, R. M. 2002. Towards a framework for understanding the evolution of avian migration. Journal of Avian Biology 33:433-436.

Received 15 July 2003, accepted 2 February 2004. Associate Editor: F. Moore 